\title{
Assessing Information on Food Packages
}

Clement, Jesper; Smith, Viktor; Zlatev, Jordan; Gidlöf, Kerstin; Van de Weijer, Joost

Document Version

Accepted author manuscript

Published in:

European Journal of Marketing

DOI:

10.1108/EJM-09-2013-0509

Publication date:

2017

License

Unspecified

Citation for published version (APA):

Clement, J., Smith, V., Zlatev, J., Gidlöf, K., \& Van de Weijer, J. (2017). Assessing Information on Food

Packages. European Journal of Marketing, 51(1), 219-237. https://doi.org/10.1108/EJM-09-2013-0509

Link to publication in CBS Research Portal

\section{General rights}

Copyright and moral rights for the publications made accessible in the public portal are retained by the authors and/or other copyright owners and it is a condition of accessing publications that users recognise and abide by the legal requirements associated with these rights.

Take down policy

If you believe that this document breaches copyright please contact us (research.lib@cbs.dk) providing details, and we will remove access to the work immediately and investigate your claim. 


\title{
Assessing Information on Food Packages
}

\author{
Jesper Clement, Viktor Smith, Jordan Zlatev, Kerstin Gidlöf, and Joost Van de Weijer \\ Journal article (Accepted manuscript)
}

CITE: Assessing Information on Food Packages. / Clement, Jesper; Smith, Viktor; Zlatev, Jordan; Gidlöf,

Kerstin; Van de Weijer, Joost. In: European Journal of Marketing, Vol. 51, No. 1, 2017, p. 219-237.

This article is () Emerald Group Publishing and permission has been granted for this version to appear here:

https://research.cbs.dk/en/publications/assessing-information-on-food-packages.

Emerald does not grant permission for this article to be further copied/distributed or hosted elsewhere without the express permission from Emerald Group Publishing Limited.

DOI: 10.1108/EJM-09-2013-0509

Uploaded to CBS Research Portal: January २०1९ 


\title{
Assessing Information on Food Packages
}

\author{
Jesper Clement* \\ Associate Professor, Ph.D. \\ Department of Marketing \\ Decision Neuroscience Research Cluster - DNRC \\ Solbjerg Plads 3C 3., DK-2000 Frederiksberg C \\ jc.marktg@cbs.dk \\ Viktor Smith \\ Associate professor, Ph.D. \\ Copenhagen Business School, \\ Department of International Business Communication \\ Dalgas Have 15, DK-2000 Frederiksberg \\ vs.ibc@cbs.dk \\ Jordan Zlatev \\ Full Professor, Ph.D. \\ Lund University, Centre for Languages and Literature \\ S-221 00 Lund \\ jordan.zlatev@ling.lu.se \\ Kerstin Gidlöf \\ Researcher, Ph.D. \\ Lund University, Cognitive Science Department of Philosophy \\ S-221 00 Lund \\ kerstin.gidlof@lucs.lu.se \\ Joost van de Weijer \\ Ph.D. Researcher, Linguistics and Phonetics \\ Lund University \\ joost.van_de_weijer@ling.lu.se
}

* Corresponding author 


\section{Assessing Information on Food Packages}

\section{1 - Introduction}

In today's food market, consumers increasingly base their in-store decisions on words, figures, illustrations, and other labelling attributes placed on the front of the product package rather than on exact facts about the food product, such as information usually printed on the back in product declarations (Nordfalt, 2009; Clement, 2007; Grunert \& Bech-Larsen, 2005). Particularly for new and less well-known food products, this has the consequence that consumers can misinterpret, and in the worst case, be misled by specific visually vivid elements on the package (Eden, Bear, \& Walker, 2008).

The experience of being misled may arise immediately in the store while standing in front of the shelf, or later, when consuming the product and finding a mismatch between the product's actual nutritional properties, its taste, its origin etc, on the one hand, and what the consumer expected with respect to these, on the other. Although research on behavioural decision theory finds that people have difficulty making choices in their own best interests (Hsee \& Hastie, 2006), an in-store decision based on certain elements visually highlighted on the package front could give the consumer the impression of being cheated.

All such cases of "false communication" (Habermas, 1984) are undesirable, from the point of view of both the manufacturer and the consumer. While potentially misleading elements may boost short-term sales, they will ultimately result in consumer annoyance, complaints, and a likely loss of brand confidence (Underwood, 2003).

Misleading information on packages can be of different kinds. One type, relatively easy to address, concerns factually incorrect information, for example, stating $15 \%$ fat when the product actually contains more fat. However, there are other, more complicated, cases. For example, when the front of one product package states $5 \%$ fat and this is entirely true, does this mean that the particular product is healthier than comparable ones that do not carry such a claim? The issue becomes even more complicated if the front states $30 \%$ less fat: how should this be interpreted? And what do pictures of healthy, good-looking people on the front promise?

Examples such as these are regularly claimed to be misleading, and authorities can be persuaded to intervene by consumer organizations. Yet current practices in such cases build on ad hoc, common-sense considerations, and not on systematic knowledge of the communicative 
and cognitive mechanisms triggered by such labelling elements (Smith, Clement, MøgelvangHansen \& Selsøe Sørensen, 2011). Empirical evidence that these elements can exert a potentially misleading effect is lacking.

Information may come from several in-store visual elements like hangers, floor graphics, or signs on trolleys, and research by Chandon et al. (2009) underlined how a huge range of variables might grab consumers' visual attention in different ways and influence their willingness to purchase. How people take in different visual information elements and whether they interpret them unambiguously or not is the central topic of this article. In order to maintain focus, we limit our research to labelling elements on product packages. Methodologically, the misleading potentiality of specific labelling elements is investigated in an experimental study, which is described in section 7, but first we motivate the need for the study and define the theoretical framework.

\section{2 - Use of Information for an Optimal Decision}

In-store decision processes, in which consumers interpret information displayed by food packages, have been addressed extensively in marketing and consumer behaviour research. Several studies have investigated consumers' decision-making processes, addressing the importance of comparing product attributes (Ajzen \& Fishbein, 1974; Kahn, 2005), the effect of extrinsic information such as price units (Mitchell, Lennard, \& McGoldrick, 2003; Urbany, Dickson, \& Kalapurakal, 1996), or consumers' interpretation of packaging size and shape (Wansink \& Van Ittersum, 2003; Folkes \& Matta, 2004; Raghubir \& Greenleaf, 2006). Others have investigated consumers' fast decision-making in relation to repeated purchases (Hoyer, 1984), how packaging redesign influences sales (Lee, Gao \& Brown, 2010), hedonic decisions (Holbrook \& Hirschman, 1982), or emotional responses (Bagozzi, Gopinath, \& Nyer, 1999).

Several studies on consumers' information processing and choices divide the visual stimuli into either textual elements (often described as verbal) or image elements (often described as visual). On the basis of ease of perception (Reber, Schwarz \& Winkielman, 2004), it is often predicted that images and pictures are preferred over words and text. However, in a choice set where people balance two or more specific product options against each other, they might perceive an increase in complexity from pictorial depiction and turn to the textural elements (Townsend \& Kahn, 2014). In that case, pictures are not always the optimal solution for driving sales. When used for health issues, like warnings on cigarette packaging, pictures seem to 
have a greater impact than text (Veer \& Rank, 2012), but processing such pictures requires more cognitive activity.

More cognitive activity implies a slower interpretation process (Kahneman, 2011). According to this logic, a picture should be processed more slowly than a word, which is contrary both to common sense and to findings by, for example, Luna and Peracchio (2003) underlining images to be processed faster and more automatically than words. These diversities might be founded in different contexts where picture information is used for either pushing the receiver in the direction of doing something (e.g. advertising) or the opposite, namely, preventing the receiver from doing something (e.g. warnings on cigarettes). In short, it is a matter of how people perceive and interpret what they see, which again is a matter of transforming visual input into a specific conceptual understanding (Clarke \& Tyler, 2015).

The majority of marketing research focuses on pushing impact from visual stimuli on consumer preferences, brand awareness, and willingness to buy, whereas research on the potentially misleading effect from visual elements like pictures and words is less present in the marketing literature. Analyses of misleading information have more often been carried out in the field of commercial and consumer protection law (Howells, Micklitz, \& Wilhelmsson, 2005; MacMaoláin, 2007). The assessments provided within this field are generally based on the normative and common-sense judgments of lawyers and government officials. In this field, research questions are related to the possibility of misleading consumers. In the EU, the basic criterion for product information to be considered misleading is if "it causes or is likely to cause [the average consumer] to make a transactional decision that he would not have taken otherwise" (Unfair Commercial Practices Directive 2005/29/EC, Article 6). In other words, the consumer has made a decision on false grounds.

Authorities, organizations, and retailers have introduced several signposts and labels such as "traffic lights" and "Guideline Daily Amounts" that are intended to help consumers to make better informed food choices. Yet, there is only limited evidence that better informed food choices will result in a healthier diet, or which design of a food label is best understood by consumers (Gracia, Loureiro, \& Nayga, 2009) and studies on health labels on food packages found little or no effect on choice or changes in behaviour (Borgmeier \& Westenhoefer, 2009). Consumers may even have an overbearing approach to their food choices if any health related information is visible on the package (Wilcox, Vallen, Block \& Fitzsimons, 2009). 


\section{3 - Interpreting or Misinterpreting Information}

Common to many studies on consumer behaviour and information processing is an assumption of correct and unambiguous interpretation of the stimuli. In the perspective of the EU Directive, all consumers with a certain level of knowledge are expected to perceive, interpret, and understand the visual information on the packaging at a similar level. But this is problematic as studies on eye movement find search patterns to be more variant depending on either the search task (Yarbus, 1967) or previous experience and background knowledge (Selsøe Sørensen, Clement \& Gabrielsen, 2012). Furthermore, as discussed earlier, textual and pictorial information may not attract visual attention in the same way and consumers may even have different interpretations of the very same information.

Multiple complaints of being misled are reported, but it is a complicated matter to decide whether it is the information on the product or the receiver's interpretation of it that gives rise to the misleading effect. Experimental studies found factually true information to have a potentially misleading effect on the form of what is called a "halo effect" or a "magic bullet effect" (Roe, Levy, \& Derby, 1999; van Dam \& van Trijp, 2007; Williams, 2005). These healthrelated claims on the front of the package lead consumers to expect nutritional and health benefits that have nothing to do with the claim itself; for example, that low cholesterol means low fat in general. The health halo effect was also found to be prominent in restaurants claiming to serve healthy food, resulting in people choosing unhealthier dishes compared to what they could have chosen at restaurants that do not claim that their food is healthy (Chandon \& Wansink, 2007). Similar "irrationality" was seen in another study by Wansink \& Chandon (2006), in which consumers were found to eat more if the label "low-fat" was on the packaging.

The halo effect seems to disappear when people reconsider the information, underlining that the experience of being misled may lie in an incomplete or inappropriate interpretation of the information element. Time, and especially insufficient time, spent on processing the available information was also found to influence consumers' search strategy (Pieters \& Warlop, 1999). Studies on in-store decisions also show that consumers only spend a few seconds looking for their preferred product (Hoyer, 1984; Clement, Kristensen \& Grønhauge, 2013) and they make their final decision primarily by examining the front of the packaging (Urbany, Dickson \& Kalapurakal, 1996).

Even though these marketing studies on consumer behaviour do not take the misleading potentiality into account, the insights that can be derived from consumers' often incomplete, 
cluttered, and possibly irrational ways of using visual elements on the front of the preferred product are valuable for explaining the experience of being misled.

\section{4 - The Concept of Being Misled}

One kind of misleading effect is relatively trivial, for example, when a picture of the product does not match the product inside the package. Other cases concern information elements that might not be untrue, but may give the consumer a false impression of key product properties, so that he/she may potentially be misled and feel so, while still being unable to justify this in a verbal or written statement (Smith, Møgelvang-Hansen \& Hyldig, 2010). Stated in cognitive terms, a consumer may be led to make unjustified decisions on the basis of factually true information. This could be the case when information like 15\% fibre is highlighted on the front of a package, giving rise to a fast interpretation and an unjustified decision. Information that could additionally confirm the decision is often available on the back of the package, but consumers rarely check this information in-store and the decision is mostly based on an incomplete process.

Relevance theory (Sperber \& Wilson, 1995; Wilson \& Sperber, 2004) can provide us with a framework for understanding such incomplete information processes. Briefly described, the theory claims that there are two different ways of communicating: by coding and decoding on the one hand, and by providing evidence and deriving consequences on the other. Consequences are governed by the relevance principle, according to which the receiver expects ostensive, and especially highlighted information presented in any communicative context to be maximally relevant.

Relevance is then defined as a trade-off between conceptual effects and processing effort. Given time and motivation, the receiver can achieve an indefinite amount of conceptual effects from any piece of information, but due to the trade-off, the processing stops when a good enough interpretation has been reached. This means that the information of $15 \%$ fibre can be experienced as enough and be the reason for an unjustified decision, but not an irrational decision. A fully informed consumer who subsequently may regret that he/she had not spent more time on interpreting and possibly choosing a different product can thus make an irrational decision. This, in a nutshell, is what underlies the experience of being misled. For the sake of investigating these issues empirically, we need to make an explicit conceptual distinc- 
tion. We define the concept of potentially being misled as follows:

Potentially misleading elements (PMEs) are labelling elements that are not factually false but can lead to unjustified decisions.

\section{5 - Words or Pictures as Potentially Misleading Elements (PME)}

PMEs can be placed on a scale of package information elements. At one end of this scale, we have information elements that are legally regulated and have an objective value, for example, quantity. At the other end, we have brand elements and statements like "enjoy" or "have a break", which are hard to match against any facts at all but are clearly interpreted as brand related elements. In between, we have PMEs that are neither elements with a clear objective value nor clearly related to one specific brand.

Since many packaging design elements can fit into the definition of a PME, we try to limit our focus to prototypical types of PMEs on the basis of the previously made division between text and illustrations. These two types of visual elements were also contributors to misleading in a survey based on 821 real-life cases of complaints about misleading food labelling (Smith et al., 2009). A majority of cases (87.6\%) linked misleading information to labelling elements such as the food name, text, or nutrition facts, including highlighted numerical information. In contrast, a minority $(7.7 \%)$ related complaints to pictorial information.

This difference between text and illustration can be considered surprising given the previously cited marketing literature and research emphasizing the impact of product illustrations and logos. Bone \& France (2001) found colours, pictures, and other illustrations to have a significantly stronger effect on beliefs about the product and purchase intentions than even very precise verbal information. A possible explanation for the "missing complaints" concerning pictorial labelling elements in the Smith et al. study (2009) could be that it is easier to formulate a formal complaint against a textual labelling element than against any pictorial element. A pictorial element does not in any self-evident way constitute a statement and thus can be said to lack truth conditions. What does a picture of happy people promise and does an illustration of the Italian flag on a frozen pizza truly imply that this product comes from Italy? ${ }^{1}$

\footnotetext{
${ }^{1}$ For further discussion of the role of truth assessments in communication see Carston (2002), Lyons (1977), and Messaris (1997)
} 
With respect to the textual elements, it has been shown that uncertainty about how to decode information such as $30 \%$ more or $10 \%$ less is a typical reason for inappropriate decisionmaking processes (Weber \& Johnson, 2009). These types of information are by their very nature ambiguous and consumers will have obvious difficulties relating such information to a standard or to other products on the shelf. Yet, numerical information without comparative expressions, such as $30 \%$ fibre or $100 \%$ natural, can have a similar effect, because these elements may give the impression that the product is better than alternatives in the same product category. This entails two types of PMEs, which form the basis for our experimental study:

(a) Highlighted numerical information, such as 5\% fat, 100\% fibre, or 100\% natural, which could lead to an unjustified decision due to an incomplete interpretation that the product might contain more or less of a certain ingredient and therefore be judged better than another similar product.

(b) Pictorial information with no obvious relation to the products, such as happy people or doctors in white uniforms, which could lead to an unjustified decision based on an interpretation that the product is preferred by healthy people or health-minded people.

\section{6 - Hypotheses}

The goal of the empirical study was to investigate whether PMEs of the two types can lead to an unjustified decision. We can judge that this would be the case when a participant (corresponding in real life to a consumer) chooses a product with the PME in a situation where he/she has the option to choose an alternative product of a comparable type, value, and overall design, but lacking the PME. This leads to our first hypothesis:

H1: Participants will prefer products with a PME to otherwise equivalent products.

As described in section 3, there is a relationship between insufficient time spent on processing the information on a product package and the design of the labelling elements. Taking gaze time as an indication of visual attention implies that spending more time gazing at a PME could detract attention from other information elements. If a PME draws visual attention away from other product information on the package, the impact of the unjustified decisions should become stronger. 
Whether a minimum of visual attention is required for interpreting information has been discussed (Cohen et al. 2012), yet a "second thought", that is, spending more time to interpret the information, has been shown to be a factor that moderates the halo effect (Roe et al., 1999). This is also likely to be the case for a PME, and this would be a factor that would argue for an increased impact until a certain level of visual attention. Therefore, we formulate our second hypothesis as follows:

H2: The impact of a PME will follow an inverted $U$-shaped curve in relation to gaze time: an initial increase, followed by a decrease

The presence of a PME is not a guarantee that the consumer will be misled. Even if a product with a PME has been chosen, it could have been chosen for other reasons. Repeated purchase behaviour and brand loyalty often serve as a strategy to reduce cognitive effort and to make fast decisions while avoiding information overload (Jacoby, 1974; Lennard, Mitchell, McGoldrick, \& Betts, 2001). We therefore expected consumers' previous experiences with the brand to reduce the influence of the PME. This gives rise to the third hypothesis:

H3: Prior experience with the brand will reduce the impact of a PME

Finally, in a fast decision process in front of a shelf, the PME might also become a convenient explanation for the unjustified decisions. In order to avoid cognitive dissonance, people find explanations for their choices (Cummings \& Venkatesan, 1975). The ultimate misleading impact of a PME may occur in a situation where an alternative product without a PME could be chosen but is not, and the consumer motivates their choice by referring to the PME. Our fourth hypothesis is:

H4: Participants who have been exposed to a PME will tend to justify their decision with reference to the PME.

\section{7 - Method}

We performed a combined lab experiment using eye tracking followed by retrospective interviews. The method has been widely used for both retail in-store experiments (Clement, 2007) and for combined lab and in-store settings (Graham, Orquin \& Visschers, 2012). Monitoring participants' visual attention enables us to identify exactly which part and which element of the packaging label has been interpreted and has potentially influenced the decision. 
In a combined experiment, 37 pairs of common food products from ordinary Danish supermarkets were shown to 81 participants. The products were carefully selected so that they would form pairs, corresponding in terms of the type of food and having nearly identical ingredients and volumes. For example, if the product to the right was organic, then the product to the left was organic as well, and if the product to the right was low-fat, then the product to the left was low-fat too.

\section{1 - Stimuli}

Digital photos of the package front were produced, resulting in outline images similar to those found in e-shopping. For all pairs of products, we made sure that a PME was only present on one of the products. If present on both packages, the PME was digitally removed from one of them. This made series of pairwise products, only one of which bore a PME, which could be either a numerical labelling element or a product-unrelated illustration (Figure 1).

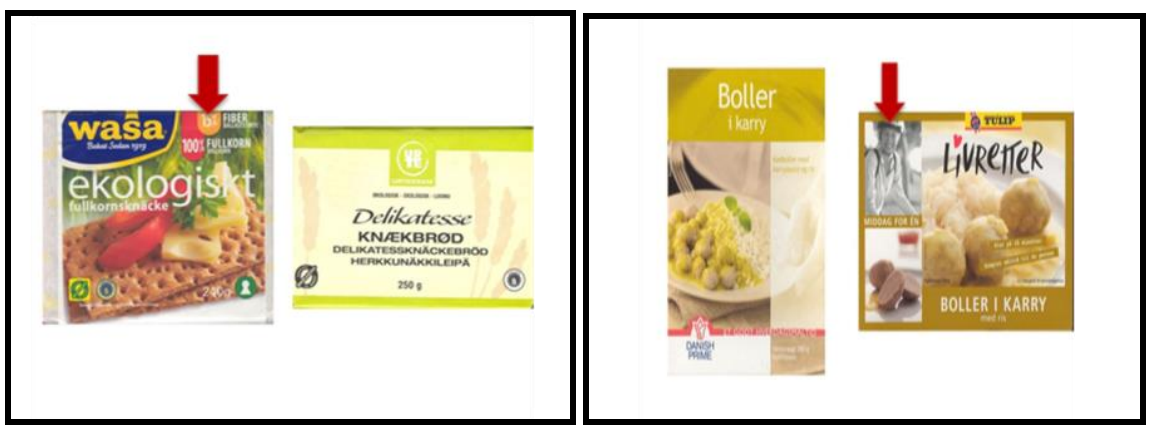

Figure 1: The arrow indicates a PME, either a numerical element (left) or a product-unrelated illustration (right)

We then duplicated the series of products into two (series A \& B), and made sure that if the PME had been present on one product in series $\mathrm{A}$, it was now present on the other product in series B (Figure 2). The photo manipulation was done digitally by a professional graphic designer to make sure the products still looked realistic. A manipulation check was made with printed versions to see if people would notice anything strange about the picture. 


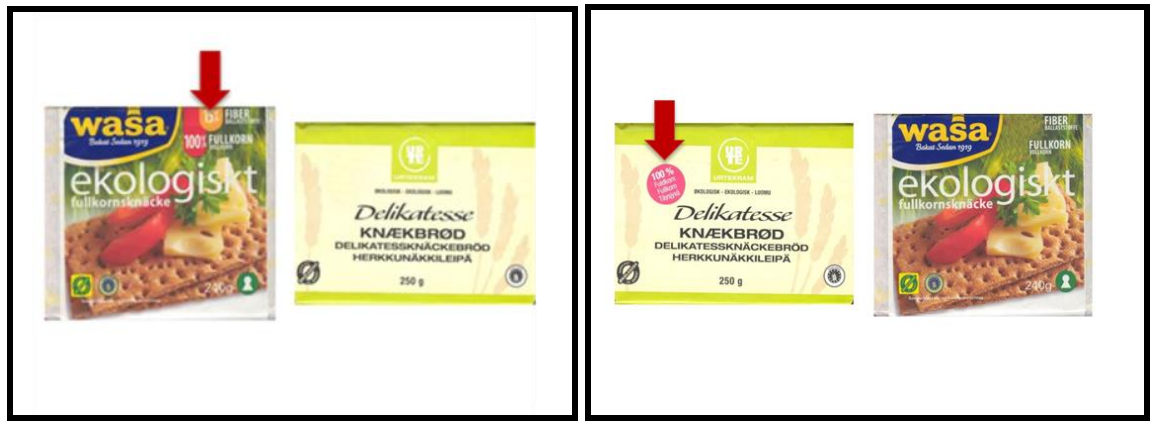

Figure 2: The arrow indicates the PME on only one of the products, either in series A (left) or in series $B$ (right)

After a pilot test, we completed both series, now containing 27 pairs of daily products like bread, fruit juice, sweets, and ready meals in which one had a PME. Another 10 pairs of products without any PMEs constituted fillers to blur the intention of the experiment, and all pairs of products were shown in a randomized order to minimize any possible spin-over effect from one stimulus to the next and to ensure the internal validity (Zikmund and Babin, 2013).

\section{2 - Participants}

A total of 81 participants completed the experiment; 42 participants viewed series A and 39 viewed series B. The participants were recruited from among business school students and came to the lab individually in order to ensure independent observations. They were compensated for their time and effort with a cinema ticket. Of the participants, 60 were female and 21 were male, with ages ranging from 18 to 36, giving an average age of 23.4 years.

Before the start of the experiment, the participants were verbally informed of their task without revealing the content and purpose of the study. Each participant was asked to sign a declaration with identical terms and was told that he/she was free to stop the experiment at any time. After the experiment (eye tracking part + retrospective interview), we debriefed each participant by giving detailed information about the study.

\section{3 - Procedure for eye tracking}

Eye tracking was the first part of the experiment, using a 19" computer screen with the SMI 60Hz. RED tracker. The participant was presented with either product series A or product series B. The participant was welcomed and placed in front of the tracker with his/her back to the eye tracking operator, who gave the following task instructions (here translated into English): "Imagine that you are going shopping for a weekend trip. You need different kinds of food products and maybe something for your sweet tooth as well. You will now go on a virtual shopping tour, 
where you will be presented with alternative products. Select the product that you would most likely choose, if you were to choose the healthier of the two."

The reason for asking participants to use the criterion of healthiness for their choice was to make sure that all participants had the same background for their decisions, and that the choice was less influenced by other personal preferences like taste or brand preferences. For that reason, no information was given about the price of the products and participants were told not to worry about any price level. Nor should they pay attention to a certain combination of the food products in relation to a recipe or a meal.

The eye tracking session started with a preliminary presentation of three pairs of products, which was meant as a "warm-up", followed by a nine-point calibration. During the "warmup", the participant also became accustomed to pressing one of two coloured keys on the computer keyboard, indicating whether the participant preferred the product on the left or the one on the right.

Each product stimulus was preceded by a white screen with a black fixation cross " + " in the middle in order to ensure a similar initial fixation point for all participants. The product stimulus was then presented for eight seconds, corresponding to the average decision time for in-store purchases (Hoyer, 1984; Clement, 2008). Following this, a white screen appeared, and after pressing one of the two keys, the fixation cross screen appeared again, introducing the next pair of products.

\section{4 - Procedure for retrospective interview}

The second part followed immediately after the eye tracking session and was formed as a structured interview in which the investigator asked the participant to give reasons for his/her choices. The retrospective interview was split into two parts, with the last part involving a replay of the eye tracking video showing the participant's eye movements.

First, one pair of products was shown on the screen again, and the participant was asked whether he/she remembered which one he/she had chosen. Then the participant was asked whether he/she was familiar with the chosen brand. The term familiarity was explained to the participants as whether they had tried, tasted, or used the specific brand. Third, the participant was asked to motivate his/her choice using a list of six predetermined options: I chose the product because of (1) the brand/logo, (2) the origin, (3) the package design, (4) the claim, (5) the signpost labels, or (6) other options. This was repeated for each of the 37 pairs of product stimuli.

Second, the investigator showed a so-called heat map (Figure 3), which is a visual representation of the participant's own eye movements and fixation lengths for each particular pair of 
product stimuli. This provided the participant with an aided memory recall when commenting on his/her choice. The investigator asked the participant whether the graphic element that had received most visual attention had influenced the decision process - irrespective of whether it was a PME or not. One of three predetermined explanations for the influence could be selected from: (1) yes, positively, (2) yes, negatively, and (3) no influence. If the most gazed element was a PME, this was noted. Otherwise, the participant was asked whether he/she considered the PME to have influenced the decision, and the same three predetermined options were available. This was repeated for each of the 37 pairs of product stimuli.

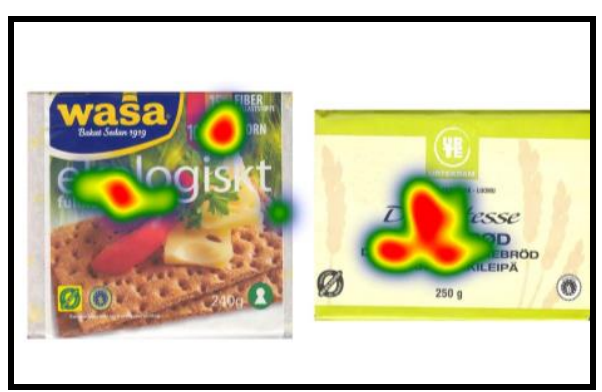

Figure 3 the heat map

Finally, the participant was asked how often he/she shopped; the possible answers were: (1) less than once, (2) once, or (3) more than once a week. The data from the post-hoc interview were carefully noted and coded into an Excel sheet. Data from the eye tracker were automatically filed in BeGaze software from SMI, suitable for interpreting eye tracking, and finally exported to the Excel sheet.

\section{5 - Framework for statistical analysis}

Predictors included whether the PME was pictorial or numerical, how many times and for how long the participant looked at the PME, and the age of the participant. The effects of the predictor variables were tested in multilevel logistic regression analyses. In these analyses, the effects of the main variables were tested while controlling for the random effects of participants and test items. The significance of a predictor was determined as the improvement of the regression model after the predictor of interest had been added. This improvement was calculated as the difference between deviance statistics associated with and without the predictor. This difference follows a chi-square distribution, and it is the value of chi-square that is reported in the results section below. As measures of effect size are not well established for 
this type of analysis, compared to, for instance, multiple R-squared for an ordinary regression analysis (Hosmer \& Lemeshov, 2000), we do not report any.

\section{8 - Findings}

The structure of this section follows the order of the hypotheses and consists of three parts. In the first part, we determine whether the presence of a PME influenced the participants' choices. In the second part, we look at moderating variables that play a role in the choice of a product with a PME, and in the third part, we analyse participants' motives on behalf of the retrospective interviews that were performed as the last part of each experiment session.

\section{1 - Do participants prefer products with a PME?}

Each series (A and B) consisted of 37 pairs of products; yet one stimulus pair was later excluded from the data because it had a pictorial as well as a numerical PME; this left 36 product pairs for the analysis, yielding a total number of responses of $36 \times 81=2916$. For further statistical analyses, we categorized the stimuli pairs depending on whether the PME was on the product to the right or the one to the left. For 42 participants, 16 stimuli had the PME on the product to the left, and 11 on the product to the right. For the remaining 39 participants, 15 stimuli had the PME on the product on the left, and 12 had the PME on the product to the right. This imbalance was caused by challenges in digital manipulation due to the specific graphic design on some of the products. An overview of the dataset for all responses during the first part of the experiment (eye tracking) shows whether the product to the left or the product to the right was preferred (Table 1). Further, it shows whether the stimuli pairs had no PME, a PME on the product to the left, or a PME on the product to the right. The number of responses refers to responses for 36 stimuli pairs of products. 


\begin{tabular}{|c|c|c|c|c|}
\hline & No PME & $\begin{array}{l}\text { PME on the } \\
\text { product to the } \\
\text { left }\end{array}$ & $\begin{array}{l}\text { PME on the } \\
\text { product to the } \\
\text { right }\end{array}$ & Total \\
\hline $\begin{array}{l}\text { Preference for the } \\
\text { product to the left }\end{array}$ & 334 (46\%) & $776(62 \%)$ & $384(41 \%)$ & 1494 \\
\hline $\begin{array}{l}\text { Preference for the } \\
\text { product to the right }\end{array}$ & 395 (54\%) & $481(38 \%)$ & $546(59 \%)$ & 1422 \\
\hline Total & 729 & 1257 & 930 & $N=2916$ \\
\hline
\end{tabular}

Table 1: Response summaries 
Table 1 shows that participants more often chose the products with the PME, and the analysis demonstrated that the placement of the PME had an overall significant effect on the choice $\left(\chi^{2}=11.621, \mathrm{df}=2, p<0.003\right)$. A correlation can be seen between a preference for a product to the left or the product to the right and whether the PME is placed either to the left or to the right. In the column for product pairs with no PME, the figures show that participants prefer the products to the right. These pairs of products were solely used as fillers; for the further analysis, we excluded these stimuli, leaving us with 2916-729 $=2187$ responses.

We then tested whether this preference for products with a PME stemmed from either numerical PMEs or pictorial PMEs. The eye tracking measurements showed that the participants gazed at a PME at least once in approximately $64 \%$ of the trials. Of the numerical PMEs, $42 \%$ were ignored, compared to only $22 \%$ of the pictorial PMEs. The average gaze time on pictorial PMEs was also longer (3.21 fixations, $861 \mathrm{~ms}$ ) than that on numerical PMEs (2.18 fixations, 769 $\mathrm{ms})$.

In spite of the fact that pictorial PMEs apparently drew more of the participants' attention than numerical PMEs, they did not cause the participants to select the PME product more often but actually less often, as shown in Table 2. However, according to the statistical analysis, this difference was not significant $\left(\chi^{2}=0.984, \mathrm{df}=1, p=0.321\right)$.

\begin{tabular}{l|c|c|c} 
& Numerical PME & Pictorial PME & \\
PME product & $956(62 \%)$ & $366(56 \%)$ & \\
chosen & $583(38 \%)$ & $282(44 \%)$ & $N=2187$ \\
Alternative & &
\end{tabular}

Table 2: Types of PMEs and their influence on product choice

From the results in Table 1, we can see that participants preferred products with a PME, and from Table 2, that both numerical and pictorial elements have an influence. We interpret these results as supporting hypothesis 1 , stating that people prefer products with a PME to otherwise equivalent products. The results also reveal the two types of PMEs to have analogous effects, even though the numerical type seems to have a slightly higher impact on participants' preferences than the unrelated pictorial information. 
At first glance, this result of textual information having a higher impact than pictorial may seem surprising. However, it might stem from a moderating effect, where information that is considered irrelevant or difficult to interpret is filtered out. We will explore this further in the following sub-section.

\section{2 - Moderating variables on the impact of a PME}

A participant's visual attention is the focus of this part, where we analyse whether the PME was gazed at or not. There are several ways to measure gazing at the PME: (1) to measure whether a participant had gazed at the PME or not (yes/no), (2) counting numbers of fixations on the PME, (3) measuring the total gaze time on the PME, (4) measuring the time to the first fixation on the PME, and lastly, (5) measuring the average gaze time on the PME.

Data for all five ways proved to be closely related and therefore, we chose the yes/no category as a point of departure. A fixation above $100 \mathrm{~ms}$ implies that a person is able to process the information consciously (Horowitz and Wolfe, 1998), and in the eye tracking software, an eye fixation longer than $100 \mathrm{~ms}$ was set as a minimum for counting as an eye fixation (Duchowski, 2003). As can be seen from Table 3, there was an overall preference for the PME product and this preference was even more evident if the participant had gazed at the PME. According to the statistical analysis, this effect was significant $\left(\chi^{2}=30.411, \mathrm{df}=1, p<0.01\right)$.

\begin{tabular}{l|c|c|c} 
& $\begin{array}{c}\text { Gazed at the } \\
\text { PME? }\end{array}$ & $\begin{array}{c}\text { Gazed at the } \\
\text { PME? } \\
\text { NO }\end{array}$ & YES \\
PME product & $414(52 \%)$ & $908(65 \%)$ & \\
chosen & $377(48 \%)$ & $488(35 \%)$ & $N=2187$ \\
Alternative & &
\end{tabular}

Table 3: The effect of gazing at a PME

We pursued the effect of gaze by examining the relation between visual attention to the PME and the choice of the participant. Due to a close correlation between the total fixation time and the number of fixations $(\mathrm{p}<0.0001)$, we chose the number of fixations for this analysis; the results are shown in Table 4 . 


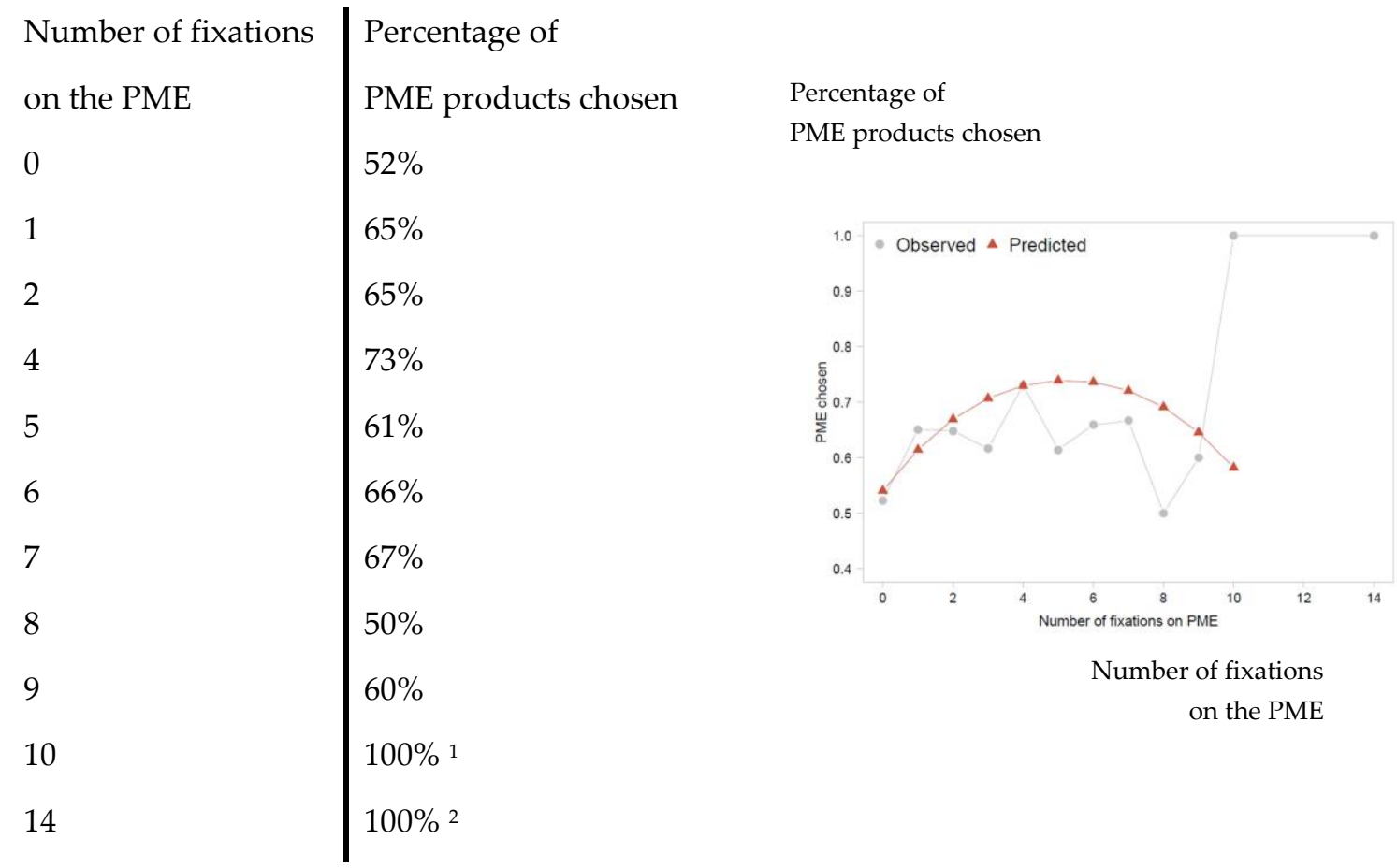

Table 4: The effect of gazing at the PME, shown in percentage and graph

${ }^{1}$ only 2 observations with 10 fixations

${ }^{2}$ only 1 observation with 14 fixations

Of the 2187 responses, $791(27 \%)$ had zero fixations on the PME. This does not imply that the participants did not make use of the information embedded in the PME; it is possible that they noticed the PME without fixating on it for longer than $100 \mathrm{~ms}$. As can be seen from Table 4 , the relation between gaze time (from 0 to 9 fixations) and the percentage of selected PME products shows that participants with four fixations on the PME are the most likely to select the PME product. This lends support to the second hypothesis that PME impact will follow an inverted U-shaped pattern. The curvilinear effect of fixations on participant choice was tested by adding a polynomial effect of the number of fixations on choice. For this analysis, the one case with 14 fixations on the PME was excluded, as it might exert a disproportionate influence on the analysis outcomes. The results of the analysis showed that the linear and the quadratic components of the predictor were both significant (linear effect: $\mathrm{EST}=0.335, \mathrm{SE}=0.076, \mathrm{z}=$ 4.404, $\mathrm{p}=.000$; curvilinear effect: $\mathrm{EST}=-0.032, \mathrm{SE}=0.011, \mathrm{z}=-2.781, \mathrm{p}=0.005$ ). 


\section{3 - Justifying a decision with reference to a PME}

The retrospective interview in the last part of the experiment gave us data about the participants and their motivation for choosing a certain product. The participants indicated their main motivation for product choice by selecting one or more of six options: claim, brand, origin, atmosphere, signpost labels, and other. Table 5 shows how often each of these alternatives was selected.

\begin{tabular}{l|l} 
Alternative & Frequency \\
claim & $564(0.19)$ \\
brand & $409(0.14)$ \\
origin & $19(0.01)$ \\
atmosphere & $1242(0.43)$ \\
signpost labels & $91(0.03)$ \\
other & $1005(0.34)$ \\
&
\end{tabular}

Table 5: Participants' motivations for their choices. As more than one option could be selected per product, the sum of the frequencies is larger than the total number of trials, and the proportions do not add up to 1.

The analysis can be divided into the following predictors: 1) whether or not the PME was pictorial, 2) whether the participant was a man or a woman, 3) the influence of age, 4) whether or not the participant was familiar with the brand, 5) whether the product with the PME was on the left or the right side, 6) whether the participant had gazed at the PME or not, and 7) how often the participant shopped. The effects of these variables were used as predictors in a multilevel logistic analysis. The results are displayed in Table 6.

\begin{tabular}{l|l|l|l|l} 
& Coefficient & $\begin{array}{l}\text { Standard } \\
\text { error }\end{array}$ & $z$-value & $p$-value \\
Intercept & 0.466483 & 0.551922 & 0.845 & 0.398 \\
1. pictorial (Yes-No) & -0.419259 & 0.334559 & -1.253 & 0.210 \\
2. sex & -0.090791 & 0.127958 & -0.710 & 0.478 \\
3. age & 0.003026 & 0.017193 & 0.176 & 0.860
\end{tabular}




\begin{tabular}{l|l|l|l|l} 
4. familiar with the brand (Yes-No) & -0.042292 & 0.110644 & -0.382 & 0.702 \\
5. placement of PME (Left-Right) & 0.167036 & 0.309848 & 0.539 & 0.590 \\
6. gazed at PME (Yes-No) & $\mathbf{0 . 6 7 7 1 3 0}$ & $\mathbf{0 . 1 2 0 0 3 3}$ & $\mathbf{5 . 6 4 1}$ & $\mathbf{0 . 0 0 0}$ \\
7a. shopping frequency: once & -0.481088 & 0.295518 & -1.628 & 0.104 \\
7b. shopping frequency: more & -0.381077 & 0.262500 & -1.452 & 0.147
\end{tabular}

Table 6: Variables able to predict preference for a product with a PME

As can be seen from the results in Table 6, the only predictor that was significant in the analysis was whether or not the participant had gazed at the PME. This result strengthens the finding from our previous analysis, namely, that PMEs did indeed play a role in the participants' choices. We expected to find a reducing impact of PMEs if the participant had prior experience with the brand, but this was not the case. For both groups expressing either familiarity or unfamiliarity with the chosen brand, almost the same share favoured the product with a PME (Table 7).

\begin{tabular}{|c|c|c|}
\hline & $\begin{array}{c}\text { Familiarity } \\
\text { with the chosen } \\
\text { brand }\end{array}$ & $\begin{array}{l}\text { No familiarity } \\
\text { with the chosen } \\
\text { brand }\end{array}$ \\
\hline $\begin{array}{l}\text { PME } \\
\text { product chosen }\end{array}$ & $650(61 \%)$ & $671(59 \%)$ \\
\hline $\begin{array}{l}\text { Alternative } \\
\text { product chosen }\end{array}$ & $408(39 \%)$ & 457 (41\%) \\
\hline
\end{tabular}

Table 7: Influence of product knowledge on choice

${ }^{1}$ As there was one missing value, the numbers do not add up to 2187

The lack of significant influence from familiarity with the brand to reduce impact of the PME provided negative evidence for our third hypothesis.

In the retrospective interview, the participants were also asked whether they thought they had been positively influenced, negatively influenced, or uninfluenced by the PME on the 
product of their choice (Table 8).

\begin{tabular}{|c|c|c|c|c|}
\hline & $\begin{array}{c}\text { Negatively } \\
\text { influenced by the } \\
\text { PME }\end{array}$ & $\begin{array}{c}\text { Not } \\
\text { influenced by the } \\
\text { PME }\end{array}$ & $\begin{array}{c}\text { Positively } \\
\text { influenced by the } \\
\text { PME }\end{array}$ & \\
\hline $\begin{array}{l}\text { PME } \\
\text { product chosen }\end{array}$ & $29(25 \%)$ & $516(46 \%)$ & 777 (82\%) & \\
\hline $\begin{array}{l}\text { Alternative } \\
\text { product chosen }\end{array}$ & 85 (75\%) & 607 (54\%) & $173(18 \%)$ & $N=2187$ \\
\hline
\end{tabular}

Table 8: The expressed influence of a PME on choice

A majority of the participants (1123) reported that they had not been influenced by the PME and findings for this group show an equal distribution between preferences for products with PMEs and preferences for products without PMEs. For the two remaining groups, a minority (114) said that they were negatively influenced, while 950 times they said that they were positively influenced. They also express a divergence between the influence of the PME and their choice, found in the mismatch between expressing a positive influence of a PME but preferring the product without the PME, or expressing a negative influence of the PME but still preferring the product with the PME. However, a majority of the participants who did choose a PME product also expressed having been positively influenced by the PME. We tested the influence of PMEs in a multilevel regression analysis; the results are displayed in Table 9.

\begin{tabular}{l|l|l|l|l} 
& Coefficient & Standard error & $\mathrm{z}$-value & $\mathrm{p}$-value \\
Intercept & -0.1465 & 0.1559 & -0.940 & 0.347 \\
Influence - negative & -1.0642 & 0.2454 & -4.337 & 0.000 \\
Influence - positive & 1.7797 & 0.1287 & 13.833 & 0.000
\end{tabular}

Table 9: Results of the regression analysis

The coefficient for the intercept in Table 9 represents the category of participants who said that they had not been influenced by the PME. This coefficient is not significant, which indicates that the difference between the frequencies in the middle columns in Table 8 is not sig- 
nificant. The other two coefficients are significant, indicating that participants who said that they were positively influenced by the PME indeed chose the product with the PME more often, and the participants who reported that they were negatively influenced by the PME chose the alternative product significantly more often.

These findings support the fourth hypothesis, stating that people who have been exposed to the PME will justify their decision with reference to the PME. Either the subject was aware of the influence of the PME during the actual choice and reports this in the interview, or he/she may not have been explicitly aware of this influence, but to avoid cognitive dissonance, rationalizes his/her choice post-hoc by referring to the PME.

\section{9 - Conclusion and Discussion}

In our experimental study, we found that potentially misleading elements (PME) on food packages have the ability to influence a person's preference for a product. The two types of PMEs - textual/numerical and pictorial - were found to have analogous effects, even though the numerical type seemed to have a slightly higher impact on participants' preferences than the unrelated pictorial information.

From previous marketing research (Townsend \& Kahn, 2014) we could have expected the opposite effect, with a stronger effect of illustrations compared to text. One reason for our findings may lie in the fact that a simple numerical element, like $15 \%$ less fat, on a package can be interpreted or misinterpreted more easily than a whole sentence trying to clarify how and against what less is measured. Reading sentences requires more cognitive effort (Kahneman, 2011) as they have to be processed sequentially and compositionally in both structure and content. A picture, on the other hand, is often claimed to be "worth a thousand words" but it might also have a limit for exact and correct information (Chun-Tuan, 2006). Pictures are usually vaguer that linguistic statements, and may give rise to numerous associations. Ultimately, this may diminish their misleading potential. The effects of the unrelated product pictures used in our study were rather similar to those of Winkielman et al. (2003), who found that unrelated information reduced the ability to judge objects. Pictorial elements like smiling people on an ordinary daily commodity can be perceived as unrelated and therefore more difficult to interpret in the particular context. Consumers will then spend time thinking twice to get the meaning. In contrast, a simple numerical element can be interpreted easily, without fostering any curiosity, as it has higher relevance, according to the predictions of relevance 
theory (Sperber and Wilson, 1995). In other words, it yields greater contextual effect for less effort (see Section 4).

Giving the PME a second glance and taking the time to make a deeper interpretation was found to moderate its misleading impact. The visual attention and the impact of the PME reached a peak at four fixations, followed by a decreased impact with more fixations. This indicates a deeper reflection on the content and the nature of the actual element. A picture of happy people on a product might at first glance give rise to an over-interpretation; in our context, an interpretation of a healthier product. Looking more closely at the picture and for a longer time may reduce this over-interpretation. This is consistent with findings on the halo effect showing that time is a moderating factor (Roe et al., 1999) and that people only draw on their fluency when the informational value is not called into question (Reber, Schwarz \& Winkielman, 2004).

Many different stimuli in the form of graphic elements on a package compete for consumers' visual attention, and the PMEs might not be the only persuader. In real life settings, a product may be chosen for many reasons; brand elements of different kinds could also be claimed to be persuaders. People are typically not aware of this cluttered visual struggle they just try to get enough information to make what they consider to be an optimal decision. In our study, this "optimal decision" was operationalized as a choice between two equal products, which would not be subsequently regretted. Our most important finding was that gazing at the PME was the only variable that significantly predicted a preference for a product with a PME.

Importantly, just receiving visual attention does not automatically imply that the PME will evoke a positive interpretation and, in the end, a positive influence on the choice. Still, there was substantial evidence for an influence from PMEs, both related to an explicit justification in the retrospective interviews and in the short decision process $(8 \mathrm{sec}$.) in the first part of the experiment. This suggests either a greater degree of awareness during the choice or a post-hoc rationalization, or perhaps a combination of both factors.

\section{0 - Limitations and Further Research}

This study tested two specific types of potentially misleading elements that can lead to unjustified decisions, solely related to health. We still need to know if the findings from our study are transferable to other contexts and specific groups of customers. Nonetheless, the selection of products in our study was not based on factors such as product healthiness or on 
any special target groups. A study on healthiness might open up for several other discussions, for example, whether a product can clearly be categorized as healthy or not, healthiness in relation to daily intake, healthy products in relation to a diet, and many other variables that influence healthiness (Sellitto \& Pellegrino, 2014). We thus believe that the results have general significance and leave it to further research to clarify whether the impact of PMEs differs across product types, variations in needs, and types of consumers.

This study did not find evidence to support the notion that familiarity with a specific brand reduces the impact of a PME. This does not mean that a correlation between low brand knowledge and potentially being misled could not be found in future research. The fact that the respondents were young may mean that their knowledge of market diversity was less extensive than that of more experienced consumers and therefore might explain why half of the participants expressed unfamiliarity with the chosen brand. As underlined in our methodology (section 7), unfamiliarity did not imply unfamiliarity with the type of product, but solely with the specific brand. Another factor that could contribute to unfamiliarity might therefore be that some participants find the manipulated brands unfamiliar due to the manipulation. In the experiment, we tested different types of packaging design and different types of PMEs, and any experiment set-up is by its very nature based on a range of substantive judgments. We consider this experiment to be a source of inspiration for further research in the relation between PMEs and brand familiarity.

The influence of PMEs on brand evaluation and finally, on brand value has not been part of this research. This does not make the topic less relevant for marketers, and for food companies, it might become a priority in managing a brand strategy that combines consumer preferences and loyalty with measures of communicative fairness. A majority of marketing research and especially research related to promotion focuses on the ability to build up a brand (Allender \& Richards, 2012), whereas the negative impact of specific types of information on brand perception is insufficient. We need further insights into how different types of PMEs "do their job" in real life settings providing designers and manufacturers with insights into the misleading effects and preventing loss in brand equity.

\section{1 - References}

Ajzen, I., \& Fishbein, M. (1974). Factors influencing intentions and the intention-behavior relation. Human Relations, 27(1), 1. 
Allender, W.J. \& Richards, T.J. (2012). Brand Loyalty and Price Promotion Strategies: An Empirical Analysis, Journal of Retailing, vol. 88, no. 3, pp. 323-342.

Bagozzi, R. P., Gopinath, M., \& Nyer, P. U. (1999). The role of emotions in marketing. Academy of Marketing Science. Journal, 27(2), 184.

Bone, P. F., \& France, K. R. (2001). Package graphics and consumer product beliefs. Journal of Business \& Psychology, 15(3), 467-489.

Borgmeier, I. \& Westenhoefer, J. (2009). Impact of different food label formats on healthiness evaluation and food choice of consumers: A randomized-controlled study, BMC Public Health, vol. 9, no. 184

Carston, R. (2002). Thoughts and utterances. The pragmatics of explicit communication. Oxford: Blackwell.

Chandon, P. \& Wansink B. (2007). The Biasing Health Halos of Fast Food Restaurant Health Claims: Lower Calorie Estimates and Higher Side-Dish Consumption Intentions: Journal of Consumer Research, 34 (3), 301-14

Chandon, P., Hutchinson, J.W., Bradlow, E.T. \& Young, S.H. (2009). Does In-Store Marketing Work? Effects of the Number and Position of Shelf Facings on Brand Attention and Evaluation at the Point of Purchase: Journal of Marketing, vol. 73, no. 6, pp. 1-17.;

Chun-Tuan Chang (2006). Is a Picture Worth a Thousand Words? Influence of Graphic Illustration on Framed Advertisements. Advances in Consumer Research, vol. 33, no. 1, pp. 104-112.

Clarke, A. \& Tyler, L.K. (2015). Understanding What We See: How We Derive Meaning From Vision. Trends in cognitive sciences, vol. 19, no. 11, pp. 677-687.

Clement, J. (2007). Visual influence on in-store buying decisions: An eye-track experiment on the visual influence of packaging design. Journal of Marketing Management, 23(9), 917928.

Clement, J. (2008). Visual influence of packaging design on in-store buying decisions. (Ph.D., Copenhagen Business School). PhD Series, 1, 1-179

Clement, J., Kristensen, T. \& Grønhaug, K. (2013). Understanding consumers' in-store visual perception: The influence of package design features on visual attention, Journal of Retailing and Consumer Services, vol. 20, no. 2, pp. 234-239.

Cohen, M.A., Cavanagh, P., Chun, M.M. \& Nakayama, K. (2012). The attentional requirements of consciousness, Trends in Cognitive Sciences, vol. 16, no. 8, pp. 411-417. 
Cummings, W. H., \& Venkatesan, M. (1975). Cognitive dissonance and consumer behavior: A review of the evidence. Advances in Consumer Research, 2(1), 21.

Dam, Y. K. van, van Trijp, H. C. M. (2007). Branding and labelling of food products. Understanding consumers of food products. Eds. L. Frewer, H. C. M. van Trijp. Cambridge: Woodhead Publishing. 153-180.

Dickson, P.R. \& Sawyer, A.G. (1990). The price knowledge and search of supermarket shoppers, Journal of Marketing, vol. 54, no. 3, pp. 42-53.

Duchowski, A. T. (2003). Eye tracking methodology, theory and practice. London: Springer Verlag.

Eden, S., Bear, C., \& Walker, G. (2008). Understanding and (dis)trusting food assurance schemes: Consumer confidence and the 'knowledge fix'. Journal of Rural Studies, 24(1), 114.

Folkes, V., \& Matta, S. (2004). The effect of package shape on consumers' judgments of product volume: Attention as a mental contaminant. Journal of Consumer Research, 31(2), 390-401

Gracia, A., Loureiro, M. L., \& Nayga, R. M. (2009). Consumers' valuation of nutritional information: A choice experiment study. Food Quality and Preference, 20(7), 463-471.

Graham, D.J., Orquin, J.L. \& Visschers, V.H.M. (2012). Eye tracking and nutrition label use: A review of the literature and recommendations for label enhancement. Food Policy, vol. 37, no. 4, pp. 378-382.

Grunert, K. G., \& Bech-Larsen, T. (2005). Explaining choice option attractiveness by beliefs elicited by the laddering method. Journal of Economic Psychology, 26(2), 223-241

Habermas, J. (1984). Theory of Communicative Action, Vol. 1: Reason and the Rationalization of Society. Thomas McCarthy, translator. Boston: Beacon Press.

Holbrook, M. B., \& Hirschman, E. C. (1982). The experiential aspects of consumption: Consumer fantasies, feelings, and fun. Journal of Consumer Research, 9(2), 132-140.

Horowitz, T. S., \& Wolfe, J. M. (1998). Visual search has no memory. Nature, 394(6693), 575577.

Howells, G. G., Micklitz, H.-W., Wilhelmsson, T. (2006). European fair trading law: The Unfair Commercial Practices Directive. Aldershot: Ashgate.

Hoyer, W. D. (1984). An examination of consumer decision making for a common repeat purchase product. Journal of Consumer Research, 11(3), 822-829.

Hosmer, D. and Lemeshov, S. (2000). Applied Logistic Regression. New York: John Wiley and Sons. 
Hsee, C.K. \& Hastie, R. (2006). Decision and experience: why don't we choose what makes us happy?, Trends in Cognitive Sciences, vol. 10, no. 1, pp. 31-37.

Jacoby, J., Speller, D. E., \& Berning, C. K. (1974). Brand choice behavior as a function of information load: Replication and extension. Journal of Consumer Research, 1(1), 33-42.

Kahn, B. E. (2005). The power and limitations of social relational framing for understanding consumer decision processes. Journal of Consumer Psychology, 15(1), 28-34. Legrand, P. (1996): How to compare now? Legal Studies 16 (2): 232-242.

Kahneman, D. (2011). Thinking, Fast and Slow. New York: Farrar, Straus and Giroux

Lee, J., Gao, Z. \& Brown, M.G. (2010). A study of the impact of package changes on orange juice demand, Journal of Retailing \& Consumer Services, vol. 17, no. 6, pp. 487-491.

Lennard, D., Mitchell, V., McGoldrick, P., \& Betts, E. (2001). Consumers use package size to estimate weight. International Review of Retail, Distribution \& Consumer Research, 11(2), 177.

Luna, David \& Laura A. Peracchio (2003). Visual and Linguistic Processing of Ads By Bilingual Consumers, in Persuasive Imagery: A Consumer Response Perspective, Linda Scott and Rajeev Batra, eds, Mahwah, NJ: Lawrence Erlbaum (153-174).

Lyons, J. (1977). Semantics I-II. Cambridge: Cambridge University Press.

MacMaoláin, C. (2007). EU food law. Protecting consumers and health in a common market. Oxford: Hart Publishing.

Messaris, P. (1997). Visual persuasion: The role of images in advertising. Thousand Oaks, CA: Sage Publications.

Mitchell, V., Lennard, D., \& McGoldrick, P. (2003). Consumer awareness, understanding and usage of unit pricing. British Journal of Management, 14(2), 173-187.

Nordfalt, J. (2009). Unplanned grocery purchases: The influence of the shopping-trip type revisited. Journal of Consumer Behaviour, 8(1), 1-13.

Pieters, R., \& Warlop, L. (1999). Visual attention during brand choice: The impact of time pressure and task motivation. International Journal of Research in Marketing, 16(1), 1-16.

Raghubir, P., \& Greenleaf, E. A. (2006). Ratios in proportion: What should the shape of the package be? Journal of Marketing, 70(2), 95-107

Reber, R., Schwarz, N. \& Winkielman, P. (2004). Processing Fluency and Aesthetic Pleasure. Personality and Social Psychology Review, vol. 8, no. 4, pp. 364-382. 
Roe, B., Levy, A. S., \& Derby, B. M. (1999). The impact of health claims on consumer search and product evaluation outcomes: Results from FDA experimental data. Journal of Public Policy \& Marketing 18(1), 89-105.

Sellitto M, di Pellegrino G (2014). Errors Affect Hypothetical Intertemporal Food Choice in Women. PLoS ONE 9(9):

Smith, V., Søndergaard, M. Ohm, Clement, J., Møgelvang-Hansen, P., Sørensen, H. Selsøe, \& Gabrielsen, G. (2009). Fair Speak: Scenarier for vildledning på det danske fødevaremarked. [Fair Speak: Scenarios of misleading conduct on the Danish food market.] Copenhagen: Ex Tuto Publishing.

Smith, V., Møgelvang-Hansen, P., Hyldig, G. (2010). Spin versus fair speak in food labelling: A matter of taste? Food Quality and Preference, 21, 1016-1025.

Smith, V., Clement, J., Møgelvang-Hansen, P. \& Selsøe Sørensen, H. (2011). Assessing in-store food-to-consumer communication from a fairness perspective: An integrated appraach. Fachsprache - International Journal of Specialized Communication. 13(1-2), 84-106

Selsøe Sørensen, H., Clement, J. \& Gabrielsen G. (2012). Food labels - an exploratory study into label information and what consumers see and understand. The International Review of Retail, Distribution and Consumer Research, 22:1, 101-114.

Sperber, D. \& Wilson, D. (1995). Relevance: Communication and Cognition, Second Edition. Oxford: Blackwell.

Townsend, C. \& Kahn, B.E. (2014). The Visual Preference Heuristic: The Influence of Visual versus Verbal Depiction on Assortment Processing, Perceived Variety, and Choice Overload. Journal of Consumer Research, vol. 40, no. 5, pp. 993-1015.

Underwood, R. L. (2003). The communicative power of product packaging: Creating brand identity via lived and mediated experience. Journal of Marketing Theory \& Practice, 11(1), $62-76$.

Urbany, J. E., Dickson, P. R., \& Kalapurakal, R. (1996). Price search in the retail grocery market. Journal of Marketing, 60(2), 91-104.

Veer, E. \& Rank, T. (2012). Warning! The following packet contains shocking images: The impact of mortality salience on the effectiveness of graphic cigarette warning labels, Journal of Consumer Behaviour, vol. 11, no. 3, pp. 225-233.

Wansink, B. \& Chandon, P. (2006). Can 'Low-Fat' Nutrition Labels Lead to Obesity? Journal of Marketing Research, 43, 605-617. 
Wansink, B., \& Van Ittersum, K. (2003). Weight and height and shape and size: When do peripheral cues drive evaluation and consumption? Advances in Consumer Research, 30(1), 363

Weber, E. U., \& Johnson, E. J. (2009). Mindful judgment and decision making. Annual Review of Psychology, 60, 53-85.

Wilcox, K., Vallen, B., Block, L., \& Fitzsimons, G. J. (2009). Vicarious goal fulfillment: When the mere presence of a healthy option leads to an ironically indulgent decision. Journal of Consumer Research, 36(3), 380-393.

Williams, P. G. (2005). Consumer understanding and use of health claims for foods. Nutrition Reviews 63(7): 256-264.

Wilson D. \& Sperber, D. (2004). Relevance theory. In: Horn, L. \& Ward, G., eds. Handbook of Pragmatics. Oxford: Blackwell.

Winkielman, P., Schwarz, N., Reber, R., \& Fazendeiro, T. (2003). Cognitive and affective consequences of visual fluency: When seeing is easy on the mind. In R. Baatra \& L. Scott (Eds.), Persuasive imagery: A consumer response perspective (pp. 75-89). Mahwah, NJ: Lawrence Erlbaum

Wolfe, J. M. (1998). Visual search. In H. Pashler (Ed.), Attention (1st ed., pp. 13-73). UK: Psychology Press Ltd.

Yarbus, A.L., (1967). Eye Movements and Vision. Plenum Press, New York, NY. 